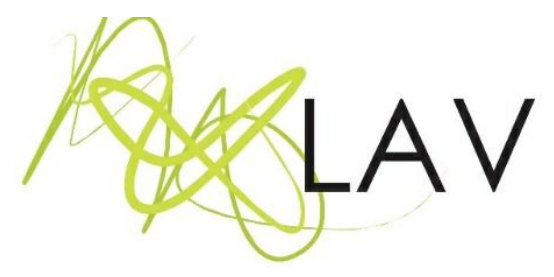

\title{
A produção de oficinas de animação com estudantes surdos na escola pública
}

The Production of animation workshops with deaf students in public education

\author{
Anelice Ribetto \\ Universidade do Estado do Rio de Janeiro \\ Arina Martinsii \\ Universidade do Estado do Rio de Janeiro
}

\section{Resumo}

Este relato de experiência é parte de uma pesquisa de mestrado concluída, um processo cartografado com estudantes surdos numa escola pública. A surdez é considerada, nesta investigação, como uma experiência visual e cultural, fora do plano medicalizante das políticas da deficiência. Assim, realiza-se um exercício cartográfico que tenciona a Pedagogia Visual como campo de estudo, propondo como intervenção a realização de oficinas experimentais de produção de vídeos de animação, que envolvem diversas técnicas visuoespaciais, corporais e de escrita. O objetivo desta reflexão consiste em pensar o processo formativo de estudantes surdos, por meio de propostas de ensino visuoespaciais, tendo como contorno metodológico um exercício cartográfico no qual se produz um dispositivo multilinear do fazer-narrar na produção de oficinas experimentais, na escrita literária de microrrelatos e na produção de narrativas imagéticas.

Palavras-chave: surdez, diferença, estudos surdos, pedagogia visual, cartografia.

\begin{abstract}
This article is a journey of researching on difference. It is part of a recent master's degree research, consisting on a mapping process (cartography) with deaf students, teachers and managers of a public school. Considering deafness a visual and cultural experience, apart from the disability plan, it consists in a cartographic exercise that perceives Visual Pedagogy as a field of study, and proposes realization of experimental workshops for the production of animation videos, involving various visuospatial, body and writing techniques. The aim of the present study is to think about the process of learning of deaf students, their visual education, by the proposal of visuospatial teaching on the creation of scripts and the production of animated short films. The methodological outline is the creation of a multilinear device of making-narrating in the production of experimental workshops with micro-narratives and image narratives.
\end{abstract}

Keywords: deafness, difference, deaf studies, visual pedagogy, cartography. 


\section{Pesquisar na diferença}

Este relato de experiência é efeito de uma pesquisa tecida na diferença, um processo cartografado com estudantes surdos numa Escola Pública, ao tecermos um exercício que problematiza a surdez enquanto uma experiência visual e cultural, fora do plano medicalizado das políticas da deficiência. Essa pesquisa foi impulsionada por uma questão movente que gerou outras também. Questão da qual não demos conta (nem tentamos), mas com a qual nos atrevemos a criar uma coreografia: Como pensar, produzir, narrar e criar propostas de ensino que sejam sensíveis com as formas singulares de aprender e de viver de estudantes surdos, arriscando produzir propostas pedagógicas que tomem formas outras?

Vivenciamos essa questão movente durante um ano e meio de encontros com estudantes surdos, ao produzir práticas que emergiram da criação de propostas pedagógicas predominantemente visuais. Propomos, como campo de intervenção, a realização de oficinas experimentais de produção de vídeos de animação, trabalho que envolve diversas técnicas visuoespaciais e de escrita. O desejo dessa pesquisa é pensar o processo formativo de estudantes surdos, sua educação visual, por meio de técnicas de ensino visuoespaciais. Esse objetivo, enunciado como desejo, é metodologicamente possível, se produzido a partir da fabricação de um dispositivo multilinear do fazer-narrar através das oficinas experimentais de animação com estudantes surdos, bem como da produção de microrrelatos e desenhografias, possibilitando produzir com os surdos uma forma de educação que Ihes toque o viver.

Ao forjar nossa pesquisa, entramos na Escola Municipal, em meio a um projeto de educação de surdos em transcurso. A escola apresentou-se como território possível para a produção desta pesquisa-escrita que problematiza a educação de surdos, uma escola de um município próximo com classes bilíngues, duas turmas em 2017 e cinco turmas em 2018, e que esteve disposta a receber e participar do projeto. Nosso projeto foi produzido entre os anos de 2017 e 2018 . Em 2017, participaram da pesquisa onze estudantes surdos e, em 2018, oito estudantes, além de professores, estagiários, equipe pedagógica e diretiva.

Compomos esta pesquisa-escrita como um exercício cartográfico, entendendo a escrita e a pesquisa como processos imbricados, ou seja, que se produzem enquanto campo de pesquisa. Esta escrita não se faz apenas no final, na análise de dados, mas é 
parte do processo de pesquisa, da produção de dados (BARROS; KASTRUP, 2009), compreendendo "o caminho da pesquisa cartográfica [como] constituído de passos que se sucedem sem se separar" (BARROS; KASTRUP, 2009, p. 59). Nesse sentido, o caminho que aqui se desenha é processual, repleto de continuidades e de descontinuidades. Portanto, esta escrita não se faz completa após a pesquisa concluída, mas produz a pesquisa e é por ela mesma produzida.

Um modo de fazer-narrar é singularmente produzido aqui: um exercício cartográfico que arrisca produzir algo que pudesse funcionar como um dispositivo (DELEUZE, 1990). Este com o fim de expandir o que se passa entre nós, dando a ver os movimentos, rebeldias, alegrias, divergências, tensões e gestos dos encontros com estudantes surdos no movimento de oficinar. Desse modo, criamos um dispositivo multilinear do fazer-narrar: oficinas, microrrelatos e desenhos.

As imagens processualmente produzidas aqui, em especial, através de desenhos e vídeos constituem a narrativa visual desta pesquisa-escrita. Compõem uma desenhografia que, junto da produção de microrrelatos, integram a força expressiva deste trabalho enquanto exercício cartográfico: aquilo que nos permite escrever na processualidade da pesquisa e que amplia as possibilidades de problematização do campo de pesquisa e do objeto que vai se forjando, à medida que a pesquisa transcorre. A produção de desenhos, vídeos e microrrelatos assume nesta pesquisa a função de dar a ver e falar uma outra 'política da narratividade' (PASSOS; BARROS, 2009).

Podemos compreender um microrrelato como uma força expressiva, próxima de um conto que é bem curto em tamanho, mas muito intenso em suas possibilidades de produção de sentidos e comunicação, capaz de dizer muito com poucas palavras (CARVALHO, 2016). A composição que fazemos com os microrrelatos nessa pesquisa- escrita busca produzir efeitos na diferença - fragmentos discursivos outros que forçam o pensamento a pensar, que buscam manter o outro como outro, que é livre para pensar e fazer disso o que quiser. Desse modo, tenciona provocar pensamento, mas sem controle de que tipo ou onde vai dar, tampouco quais conclusões se tirará, ou seja, comportando a diferença.

Os desenhos e os microrrelatos acontecem no processo da pesquisa... São muitos os papéis e também os grafites e canetas... Algo transborda para compor escritas curtas. Algo transborda em mim para compor desenhos... não é possível mais parar, a pesquisa sou eu e me domina... é necessário registrar... desenhar é meu bom modo de registro, é como atrair o movimento - que pertence ao ar - para o papel. 


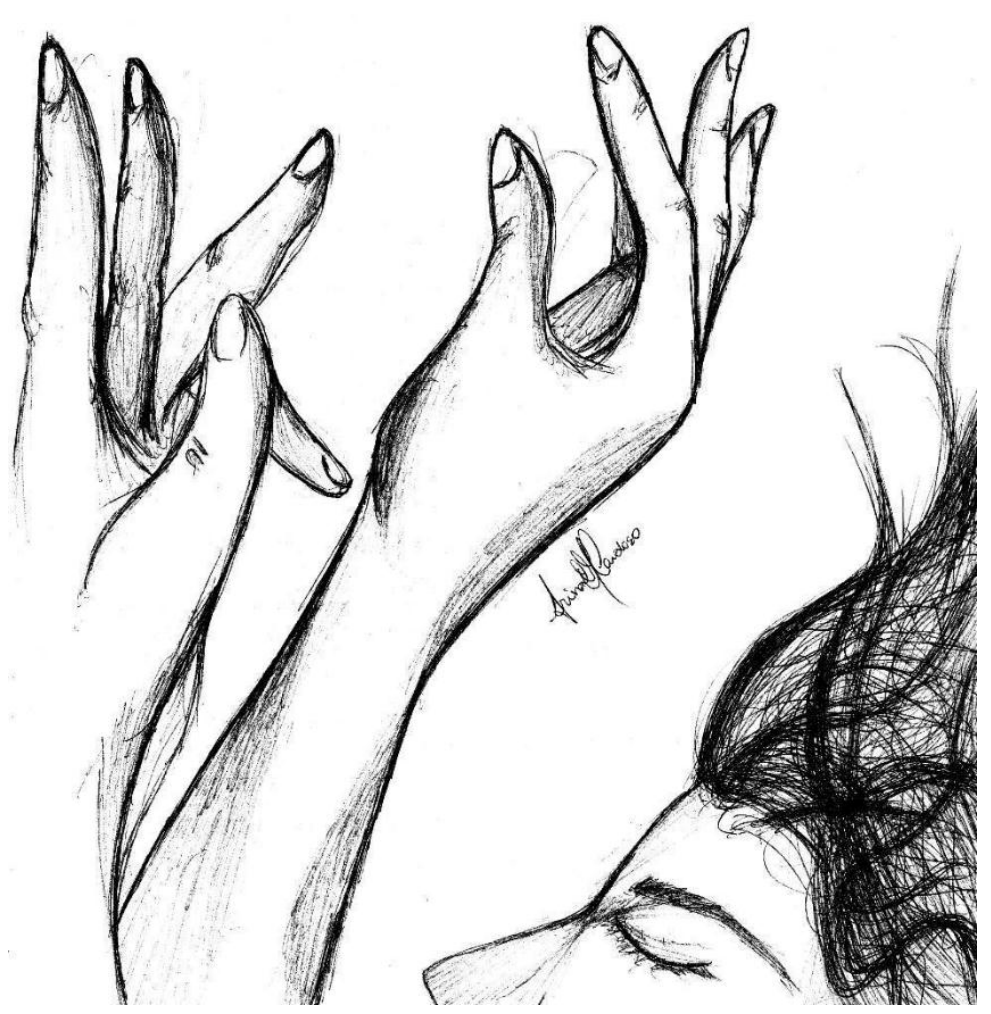

Figura 1: Desenhografia clamor, primeiro desenho Fonte: as autoras

\section{O que pode OFiciNAr?}

Trazemos para este subtítulo uma pergunta potência. Nietzsche, um 'pensador nômade', que ocupou sua vida com a questão da potência, problematiza o que aumenta ou, por sua vez, diminui a potência da vida. Inspirados nele, trazemos pra cá a preocupação com a potência. O que pode um corpo? O que pode um encontro entre pessoas que vivem a diferença nas suas condições de existência? O que podem as relações tecidas em encontros? O que podem encontros tecidos por meio de oficinas? O que pode a produção que se faz por meio das oficinas? O que pode oficinar?

seria interessante saber o que pode um corpo [uma oficina]: não para legislar sobre ele [ela], mas para poder propiciar as relações que o [a] potencializem, que aumentem sua força, os encontros que exploram ao máximo sua capacidade de ser afetado [a] e Ihe doem a força para viver mais intensamente a vida (KOHAN, 2007, p. 52).

Pensando no que pode, na potência de nossos encontros, produzimos algo que pudesse funcionar como um dispositivo multilinear a expandir o que passa entre nós, dando a ver os movimentos, rebeldias, alegrias, divergências, tensões e gestos dos encontros. Tornando-nos, enquanto território disponível à passagem, ao afetar-se, disponível à experiência, buscando nos afastar, em certa medida, das certezas e dos manuais como um exercício de dar a ver a vida e de potencializá-la. 
A partir da criação de propostas pedagógicas visuoespacias, pensadas aqui através da tessitura de oficinas experimentais, buscamos tensionar a educação de surdos frente ao padrão ouvinte. Dessa forma, pensamos a educação visual de surdos como a possibilidade de produção de um currículo outro, que tem base numa experiência outra: a experiência visual, em busca da produção de uma Pedagogia Visual (CAMPELLO, 2007, 2008). Para isso, apostamos em um verbo ação: oficinar, na busca de potência. O oficinar como um movimento que afirme "a todo instante a sua potência; que propicia aquilo do que vive: encontros alegres, forças criativas; sensibilidade atenta ao que dá vida" (KOHAN, 2007, p. 53).

Nesse exercício cartográfico, assumimos o Oficinar como um dispositivo metodológico do fazer-pensar-narrar encontros e efeitos. Abaixo, narramos através da produção de microrrelatos algumas de nossas oficinas. Apresentamos essas oficinas dividindo cada uma delas em três partes: a produção de um micro relato, a descrição de aspectos das oficinas subintitulado de "Entre nós... Acontecimentos" e, através do subtítulo "Conversando", trazemos para a conversa outros autores para discutir aspectos da visualidade na educação de surdos. Essas três partes são atravessadas pelas narrativas imagéticas produzidas ao longo desta pesquisa-escrita.

\section{Oficina... Atritar ${ }^{1}$}

\section{Calma!}

Eu vou te avisar. Deixa a mão aí... Espera eu te avisar. Quando eu avisar, você tira a mão e eu bato a foto, ok?... Não, ainda não. Espera, espera... a foto está embaçada ainda. Pode tirar. Para! Cuidado! Ah, você balançou!

Mais um pouco... Agora!

Sua mão saiu na foto! Poxa! Por que você não tirou a mão quando eu falei? (...)

Caio $^{2}$, que, antes, ficava dizendo que moldar com massinha e desenhar quadrinhos era coisa de criança, agora começa a dominar o programa e o processo de produção das fotos. Assume uma postura de liderança no grupo coordenando ações com muita empolgação.

Em seguida é a vez de Amanda produzir as fotos e ajudar na coordenação dos movimentos. Ela também está aprendendo a dominar bem esse processo. Orienta os colegas com um pouco mais

\footnotetext{
${ }^{1}$ As conversas aqui narradas através da produção literária de microrrelatos ocorreram em nossas oficinas entre os surdos, os professores e a pesquisadora em Libras.

${ }^{2}$ Aqui neste texto os nomes das crianças e adolescentes são preservados; não utilizamos seus nomes reais.
} 
de paciência que Caio.

Caio se remexe no lugar inquieto.

Depois é a vez de Augusto movimentar o personagem de massinha para a produção de mais uma sequência de fotos. Caio e outros dois colegas não gostam da ideia.

- Ele não sabe fazer.

- Ele faz tudo errado! Não vai conseguir.

O corpo de Augusto muda. Não é a primeira vez que ouve isso.

Deixa os ombros caírem, abaixa a cabeça. Volta-se pra mim, mas, constrangido, não olha nos meus olhos. Dá de ombros, vira e começa a voltar para o lugar onde estava sentado.

Me adianto. Toco nas suas costas.

- É a sua vez, não é a vez de outra pessoa.

- Mas, eu não sei.

- Você consegue aprender! E eu estou aqui pra isso, pra ensinar a vocês. Agora é a sua vez de aprender também. O vídeo só vai ficar pronto se todo mundo ajudar um pouco. Vem!

Amanda fica junto ajudando-o.

(...)

Augusto vive tempos e modos de aprender outros.

Um estudante surdo diagnosticado com deficiência intelectual leve.

(Microrrelato de pesquisa, 28 de novembro de 2017)
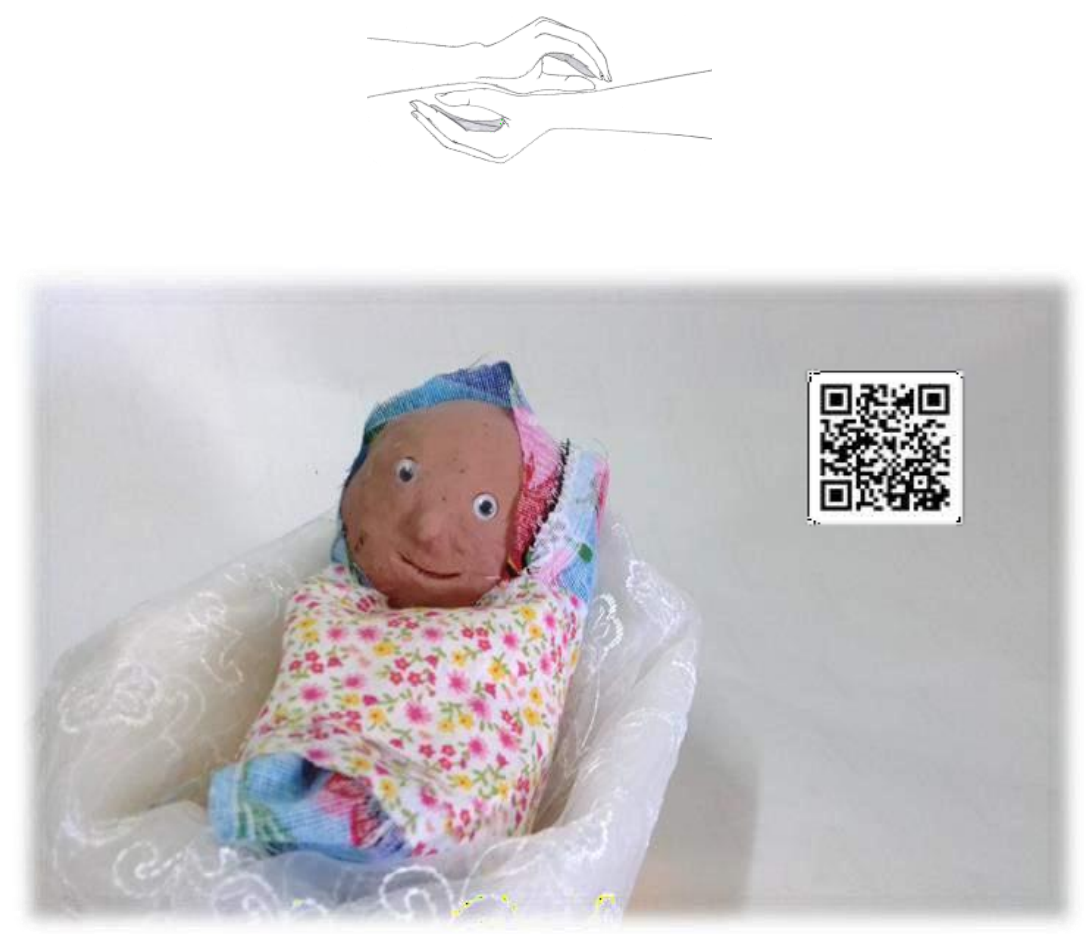

Figura 2: vídeo O Nascimento do Bebê Carlos $^{3}$

Fonte: as autoras

\footnotetext{
${ }^{3}$ Os vídeos produzidos em nossas oficinas podem ser acessados através do código em QRCode ou por este link: https://www. youtube.com/watch?v=IiNweXI37zQ\&t=12s.
} 


\section{Entre nós... Acontecimentos}

Oficinar como possibilidade.

Um ano e meio de encontros, experiências e produções. Na produção de um vídeo de animação por stopmotion há muita conversa, construção, planejamento, perdas, imprevistos... Algo que se produz ao fazer e que se escolhe ao caminhar e no contexto com os sujeitos. Muitos são os passos, mas não há um manual em que a coreografia esteja previamente composta. Existem alguns compassos, algumas orientações rítmicas iniciais e alguns repertórios experimentados de muitas formas.

Em 2017 e 2018, foram produzidos dois vídeos principais, um em cada ano, além de alguns vídeos de exercícios com materiais e com nossos corpos, brincando de animar e de criar, explorando nossos corpos e nossas ideias, bem como escolhendo algumas dessas ideias, descartando outras e inventando nas oficinas formas de aprender, de ser, de problematizar, de se alegrar e também de atritar, incomodar e tensionar. Muitas foram as experiências vividas, das quais selecionamos algumas, a exemplo do vídeo O Nascimento do Bebê Carlos, produzido no final do segundo semestre do primeiro ano de pesquisarescrever-viver, em 2017. Muitos encontros foram produzidos até chegarmos à versão final do vídeo.

Nas oficinas, estamos inteiros com nossos corpos. A arte é uma companheira constante, pois nos movimenta e nos mantém em constante curso. Em nossas primeiras oficinas, fizemos alguns exercícios de teatro brincamos, conversamos, trocamos e nos conhecemos. Iniciamos a compreensão das primeiras ideias de como produzir animações, seja com o corpo, com desenhos ou com objetos. Vimos alguns filmes que são referência na área, vídeos de experiências em outras escolas e experiências amadoras. Começamos a conhecer algumas técnicas e especificidades, experimentando-nas a partir de jogos que produzimos juntos.

Conhecemos alguns equipamentos a serem utilizados, produzimos pequenas experiências de movimento. Entendemos que para produção de um filme é necessário planejar antes, produzir roteiros, separar alguns materiais e produzir outros. Começamos a arriscar, produzindo pequenas histórias. Cada um ganhou algumas folhas de storyboard e começou a arriscar compor pequenas histórias visualmente com desenhos, com sinais e depois em português escrito. Ao chegarmos ao final de agosto do primeiro ano, em 2017, mais oficinas eram produzidas, no entanto, um tema ainda não havia sido escolhido para a produção de nosso vídeo final. Conversamos com os professores, com os alunos, vivenciando aquele espaço em suas tensões. Como cartógrafa, era necessário ajustar a lente da atenção cuidadosa ao presente. 
Algo se movia naquele ambiente e gerava conflitos, algumas dúvidas e curiosidades desestabilizavam e atritavam a casa e a escola, ora eram bem recebidas, ora não. Adolescentes descobrindo o próprio corpo, definindo os próprios gostos. Adolescentes surdos e sua sexualidade. Alguns pais com dificuldade para tratar algumas questões e os surdos tinham pouco acesso à informação em modalidade visual fora da escola sobre essas questões. No Conselho de Classe, a professora Wandréia narra essa dificuldade, apontando-a como uma necessidade de trabalho. Do outro lado da mesa, trago uma sugestão como possibilidade. Conversamos sobre a proposta de um projeto de trabalho com o tema da sexualidade que seria trabalhado por todos os professores, inclusive nas oficinas.

Paro para estudar e pesquisar conceitos, estratégias, materiais, etc. Wandréia, por sua vez, organiza o que cada um poderia trabalhar. Conversamos com os alunos e professores sobre a produção de um vídeo como forma de registro. Em meio às inúmeras discussões, propostas, produções e experimentações, inspirados em alguns vídeos vistos, escolhemos produzir um vídeo sobre o desenvolvimento de um bebê.

Os alunos produziram diferentes roteiros. Em seguida, votamos e escolhemos um. Depois, produzimos storyboards individuais e coletivos, utilizando-os como roteiro visual de um projeto. Segundo Anima Mundi (2013),

[o] storyboard é uma das etapas mais importantes na produção de uma animação. Ele é a versão em desenhos do roteiro de um filme. Contém todo o seu conceito visual como o enquadramento, cortes e movimento de câmera, além de localizar os ambientes e inserir as personagens em cena (ANIMA MUNDI, 2013).

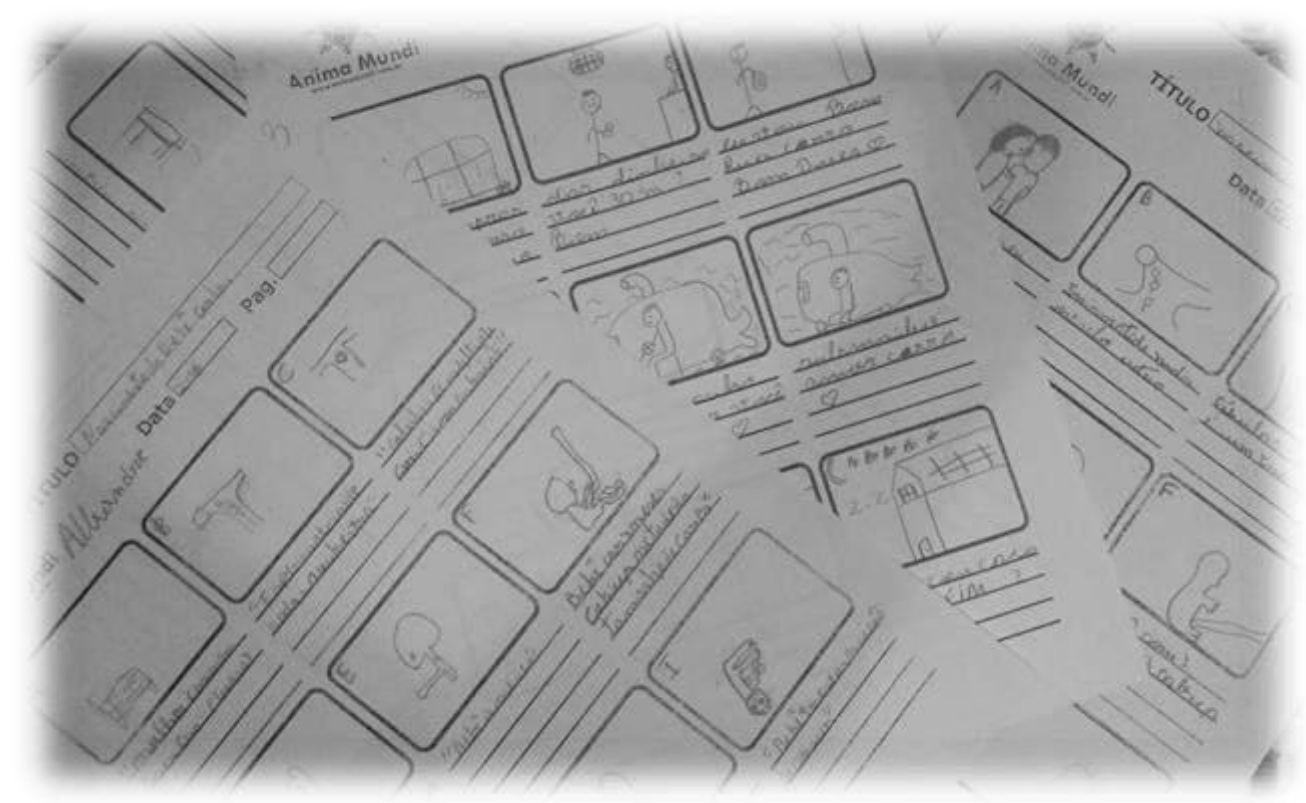

Figura 3: Roteiros

Fonte: as autoras 
Mãos na massa: selecionamos os materiais e passamos alguns encontros produzindo com massinha cada fase do desenvolvimento de um bebê e tudo mais que seria necessário.

Mãos na máquina: passamos algumas semanas aprendendo a dominar técnicas, softwares e equipamentos, produzindo as cenas, legendando e editando.

Ao longo desses processos, tivemos muitos imprevistos. Por vezes, era um inesperado dia sem aula; em outras, o único elevador da escola quebrava, o que impedia os alunos que usam cadeiras de rodas ou com mobilidade reduzida de subir para as turmas, incluindo a nossa. Outras vezes, uma prova ou outra atividade interrompiam a sequência das oficinas. Em alguns momentos, problemas técnicos com os simples equipamentos de que dispúnhamos. Algumas perdas de arquivos quase prontos, refilmagens, conflitos, acordos e desacordos, quedas de energia... Todas essas questões também compõem, pelo meio, a experiência do Oficinar.

\section{Conversando...}

Um oficinar nos conflitos, passos e descompassos da caminhada. Um oficinar na diferença que produz efeitos e que não nega ou esconde o conflito, mas gera oportunidades para que conflitos, como o narrado no microrrelato, aconteçam. E, assim, na tensão, na desarmonia, nos atritos e na friç̧ão podemos produzir oportunidades de conversar e, coletivamente, repensar o que fazemos no encontro com o outro e o que fazemos de nós mesmos.

No oficinar, outros momentos de conflitos aconteceram e acontecem, inclusive entre os mesmos alunos personagens do microrrelato anterior. A oficina é momento de tensionar a diferença e produzir pensamento, ou seja, não nos detemos em reproduzir ideais da moral ou simples proibições. Mas na diferença, na amizade e no exercício de olhar a si mesmo e o outro na relação, dar a ver e falar o dito e o não dito, atritando e arranhando para produzir algo novo em nós mesmos, algo diferente daquilo que tem sido feito de nós cotidianamente.

Assim, assumimos como um dispositivo metodológico a produção de oficinas experimentais, entendendo o movimento do oficinar como um mergulho nas experimentações, uma possibilidade para pesquisar, acompanhando processos em seus pequenos gestos e acontecimentos. Um espaço-tempo que produz relação, afetos e entres. Portanto, um dispositivo para fazer-pensar repleto de linhas do oficinar, do narrar com microrrelatos e desenhografias, uma composição ensaiada e desenhografada para produzir 
um modo outro de narrar provisoriedades. Uma composição: "uma escrita [que] faz morrer - sujeito, para fazer renascer os entretempos, entreafetos e multiplicidades." (MOEHLECKE, 2015, p. 168).

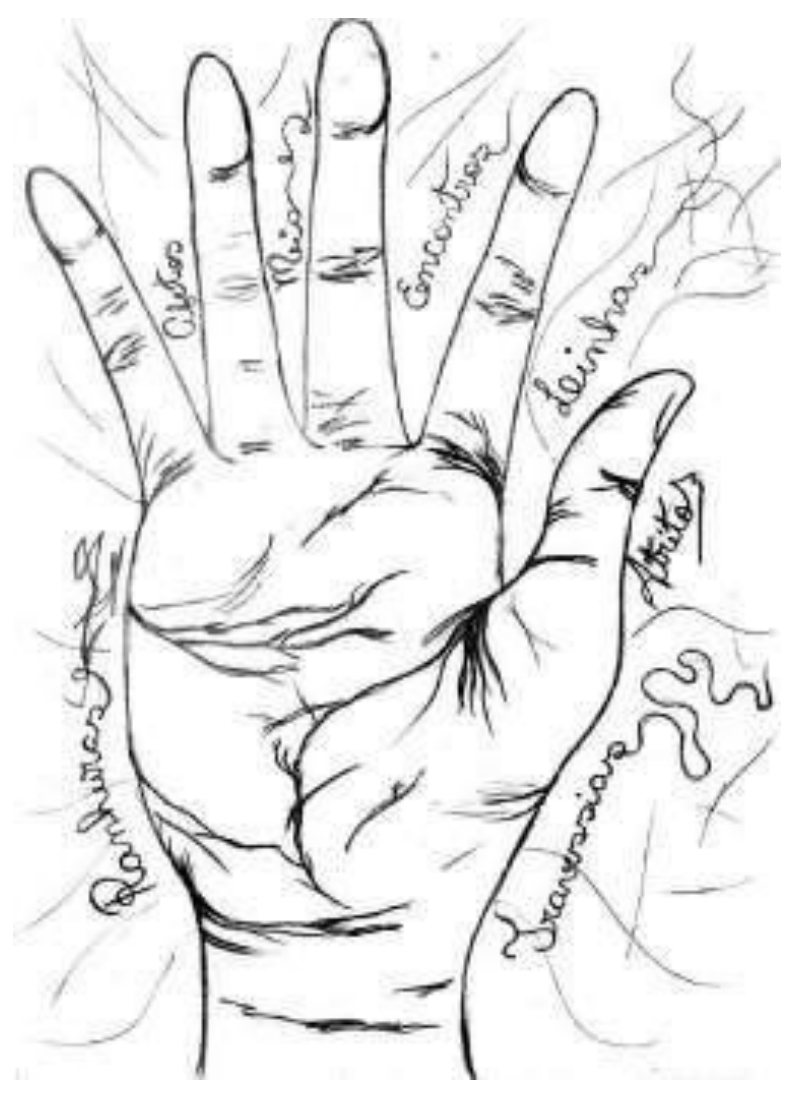

Figura 4: Desenhografia dispositivo Fonte: as autoras

"Em meio a gestos inventados, a potência do narrar invade a mesmice das significações já dadas e as faz transbordar"

(MOEHLECKE, 2015, p. 169) 


\section{Oficina... Visualidade}

Um desejo: Inserir uma música de fundo em nosso vídeo Intitulado O nascimento do Bebê Carlos...

Um problema: Não quero fazer isso sozinha, é uma produção deles, com a marca de suas mãos do início ao fim...

Uma lembrança: Kandinsky... Seus quadros dançam... ele pensava em música enquanto compunha suas telas... Músicas que dançavam em cores e formas no espaço e que eram representadas sobre a tela plana... Músicas visuais: A chave.

Seleciono de três músicas visuais. Reações: Música Verde: eles olham com atenção

Música Fada: as meninas acham fofa, sorriem uma para outra e imitam os movimentos com as mãos

Música Quadrados: espantos, caras feias, corpos se inclinam repentinamente para trás em determinadas passagens Uma explosão de efeitos: Incômodo.

(Microrrelato de Pesquisa: 07 de dezembro de 2017)

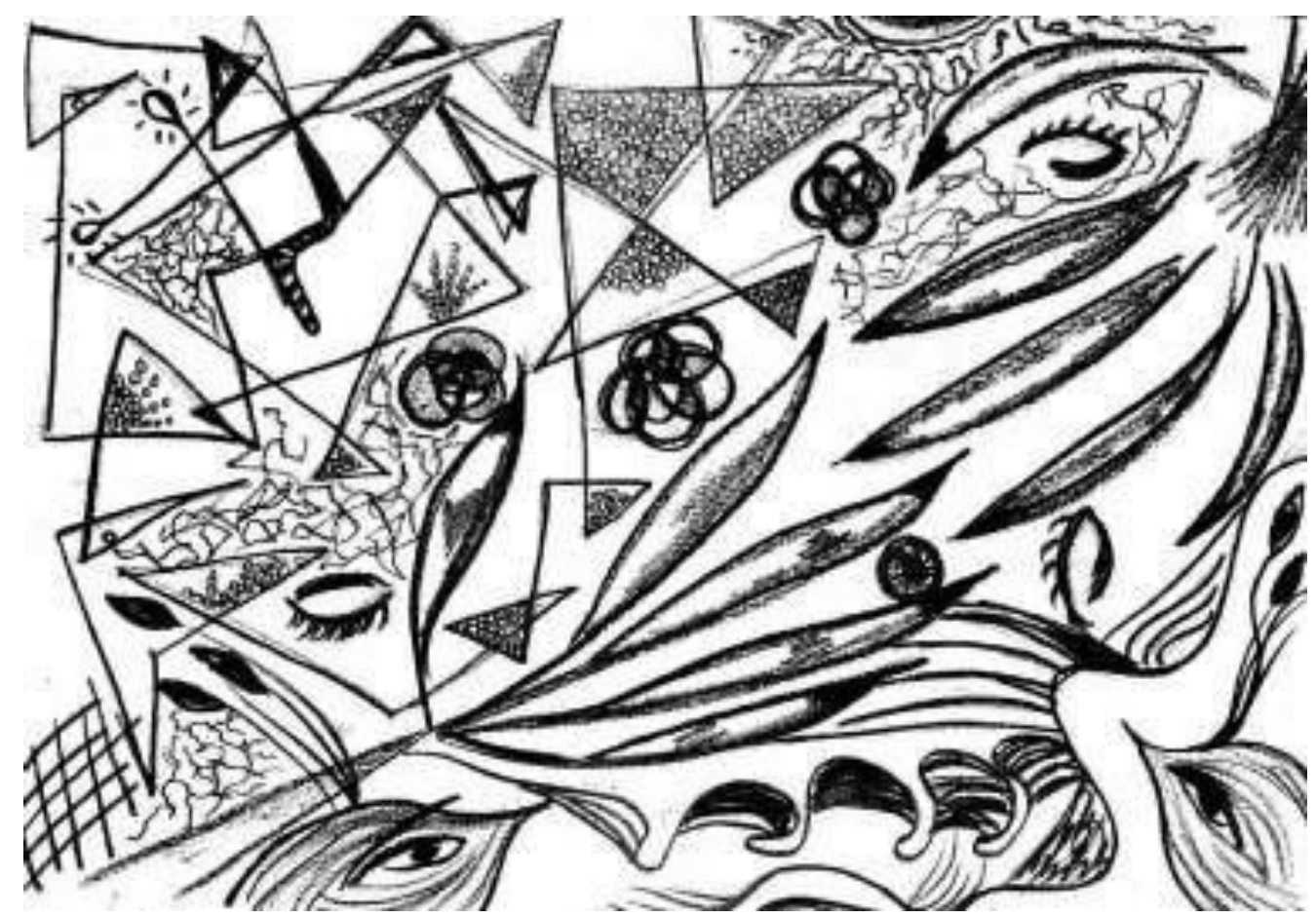

Figura 5: Desenhografia música material Fonte: as autoras

\section{Entre nós... Acontecimentos}

Dias antes do episódio narrado acima, conversei com os alunos e com a professora Wandréia sobre inserirmos uma música de fundo no vídeo que estávamos produzindo. Esse vídeo, depois de pronto, poderia ser apreciado por surdos e também por ouvintes de forma 
visual e sonora.

Em casa, penso em como fazer isso de modo que eu não fizesse essa escolha sozinha e que pudesse levar para os alunos a experiência de contato com as músicas na base a que eles têm acesso: a visual. A obra de Kandinsky e o trabalho de Oskar Fischinger me dão pistas: Música Visual. Começo a pesquisar opções e percebo o quão é difícil encontrar músicas visuais em diretórios gratuitos de livre utilização, mas há algumas opções no Youtube. Selecionei três músicas que julgo interessantes para levar para os alunos conhecerem e talvez escolherem. Escolho dar nomes fictícios de fácil apreensão às músicas, segundo características visuais das mesmas, a fim de facilitar a votação, utilizando o português escrito e sinais gráficos no quadro.

A primeira Música Visual, intitulada Verde, tem uma movimentação harmônica e intensa, compondo diferentes formas, cadenciando ritmos sobre o mesmo plano de cores: um tom de verde. A segunda, Fada, é cadenciada e harmônica, visualmente com menos variação de formas, com movimentos mais lentos, ocupando menos o plano da tela e compondo um ritmo mais leve. A terceira, Quadrados, é mais intensa e muitas formas e cores se alternam e explodem na tela. Composições mais variadas formam um ritmo mais pesado. Particularmente, a terceira música me chamou bastante atenção. Pensei que seria bastante atrativa, pois possuía mais movimentação, surpresa e ritmo. Qual foi meu espanto ao colocar na tela cada uma delas e perceber as reações deles.

A terceira música começava com composições rítmicas em forma de quadrados, mas possuía muitas variações com diferentes composições de formas, explosões em cores e luz. Os alunos começam a assistir atentos, entretanto, segundos depois, vejo seus corpos se moverem para trás de forma repentina e apertarem os olhos, franzindo o cenho incomodados. Karina sinaliza que estava incomodada, vira o rosto e logo se distrai com outra coisa. Pouco depois, outros começam a conversar paralelamente.

Na votação, a primeira música visual recebe a maioria dos votos e a terceira nenhum.

\section{Conversando...}

Problematizamos aqui a surdez como uma experiência visual, tomamos essa experiência predominante entre os surdos como base para a proposta que aqui trazemos. Compreendemos os surdos como sujeitos contemporâneos, "um sujeito híbrido, entrecruzado por diversas culturas, diversos discursos e formas de ser" (RAUGUST, 2017, p. 200). Sujeitos contemporâneos constituídos pelos discursos, por pessoas, pela língua, 
por diferentes aspectos culturais, artefatos que são produzidos e vão subjetivando. Entendemos com Veyne - citando Foucault - que

Nos processos de subjetivação, "o sujeito não é 'natural', ele é modelado a cada época pelo dispositivo e pelos discursos do momento, pelas reações de sua liberdade individual e por suas eventuais 'estetizações" (VEYNE, 2014, p. 178).

Existem diferentes formas de ser surdo e expressar a experiência da surdez. Problematizamos os surdos como grupo heterogêneo, em que a visualidade tem se mostrado aspecto importante e relevante nos estudos tecidos no campo, mas uma experiência que é múltipla, multifacetada e que não comporta movimentos de homogeneização. Os surdos são um grupo que têm como manifestação forte de sua experiência a visualidade.

Considerando os aspectos da visualidade dos surdos e as singularidades dos sujeitos envolvidos, aqui arriscamos produzir uma proposta pedagógica de base visuo-gestual por meio dos encontros experienciados em nossas oficinas. Compassamos aqui uma pesquisaescrita limitada em seu tempo, espaço e nas experiências singulares de seus sujeitos. Alguns são os aspectos amplos que assumimos, os grandes discursos agem também em nós e através de nós. Alguns dos movimentos aqui compassados podem talvez ser ampliados a outras realidades, outros são apenas singularidades. Mas seguimos implicados no compromisso rigoroso de uma pesquisa que comporta o talvez ao produzir nossas experiências e compartilhar o que nos passa, afastando-nos da busca de verdades absolutas ou de estabelecer pilares de enunciação sobre o outro.

É sobre a experiência da visualidade que nos debruçamos, experimentando nas oficinas compartilhar tempos, espaços, exercícios, cheiros, toques, gestos e afetos, todos muito permeados pela visão. Ao longo do movimento de oficinar, o modo como se afirma e se estetiza através do olhar, o modo como percebem detalhes, o modo como expressam sua corporeidade, o modo como atentam para coisas pequenas que me passam despercebidas, chamam a minha atenção.

Escolho três músicas visuais e em casa penso: "a terceira, música-visual 'Quadrados'... acho que podem gostar mais dessa, porque é tão intensa e rica em formas e movimentos! Possui muito mais ação que as demais". Na oficina, vejo em seus olhos apertados e, no movimento repentino do corpo para trás, que não. A forma de os "sujeitos surdos perceberem o mundo de maneira diferente provoca reflexões de suas subjetividades" (STROBEL, 2016, p. 44) e agora também sobre a minha própria subjetividade. Minhas tentativas e erros, minhas suposições sendo quebradas... eles percebem detalhes outros... meu olhar pelo olhar deles, sendo refinado e colocado em questão. 


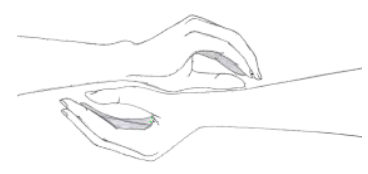

\section{Estar Juntos}

Habitando um espaço-tempo durante um ano e meio, dois anos letivos, duas turmas, dois recomeços de oficinar, mas de modos bem distintos, com algumas regularidades: mesmo dia e horário semanal para oficinar, algumas atividades novamente escolhidas e a lógica sequencial de algumas técnicas em uma caminhada repleta de singularidades. Não se aplica algo dado a priori, porque o encontro dá e faz os tempos e modos, em um movimento que produz uma pesquisa-escrita e que age nos sujeitos, no pesquisador, que me transforma por completo. Ao cartografar, ao oficinar, ao narrar de outros modos "um pesquisador se emociona e passa a amar o eterno retorno do instante replicado de múltiplos modos" (MOEHLECKE, 2015, p. 168). O corpo implicado, a nudez de velhas verdades, o enredar-se, a afetação, o emaranhar-se no campo e, ao mesmo tempo, estranhar-se.

Foram muitas as oficinas e as narrativas produzidas. Aqui destacamos apenas uma pequena parte. Nas narrativas, tematizamos. Escolhemos tematizar para falar um pouco de um turbilhão de experiências mínimas que nos acontecem no estar juntos (SKLIAR, 2010), com outros atravessados e permeados pela experiência da visão, no encontro com sujeitos constituídos, em especial, por meio de sua experiência visual.

Fabricamos nossas oficinas como uma proposta visuoespacial, todavia as experiências de trocas, conversas e aprendizagens que se compassaram não são estritas da visão; são perpassadas notadamente pela visão, mas também por um corpo inteiro em sua potência e anseios. Nossos encontros se produziram pela visão, assim como pelo toque, pelo cheiro, pelo sentir, pelo pensar, pelo atritar, pelo caminhar, pelo conversar e também pelo calar, pelo interromper.

Nos encontros oficinados, pudemos experenciar, produzir intencionalmente, imagens no contexto sócio-histórico-cultural como intervenção educativa (SANTAELLA, 2012). Penso que pudemos juntos fabricar uma forma outra, não necessariamente nova, mas uma entre tantas formas de estar juntos na educação de surdos, produzindo com eles uma forma de educação que Ihes toca viver. Além disso, inventando algo que reverbera se politicamente com mínimos ou como "podemos brincar, podemos ler, podemos sentir, podemos perceber o mundo, podemos aprender, podemos ensinar através do visual que organiza todos os olhares de forma não auditiva" (QUADROS, 2004, não paginado). 


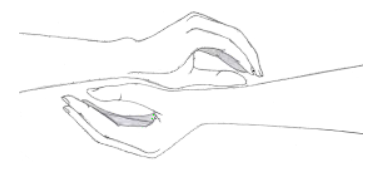

\section{Referências}

BARROS, L. P. de, KASTRUP, V. Cartografar é acompanhar processos. In: PASSOS, E.; KASTRUP, V.; ESCOSSIA, L da (orgs.). Pistas do Método da Cartografia: Pesquisaintervenção e produção de subjetividade. Porto Alegre, Sulina, 2009.

CAMPELLO, A. R. S. Aspectos da Visualidade na Educação de Surdos. (Tese de doutorado) Universidade Federal de Santa Catarina. Florianópolis, 2008.

CAMPELLO, A. R. S. Pedagogia Visual / Sinal na Educação dos Surdos. In: Estudos Surdos II / Ronice Müller de Quadros e Gladis Perlin (orgs). Petrópolis, RJ: Arara Azul, 2007.

CARDOSO, A. C. M. A produção de oficinas de animação na educação de surdos: MoVimeNTOs e possibilidades de uma proposta pedagógica visuoespacial. 2019. 150f. Dissertação (Mestrado em Educação) - Faculdade de Formação de Professores, Universidade do Estado do Rio de Janeiro, São Gonçalo, 2019.

CARVALHO, D. M. de. A importância dos microcontos para o ensino. Rio de Janeiro: CiFEFiL, 2016.

DELEUZE, G. O que é um Dispositivo: In: Michel Foucault, filósofo. Tradução de Anderson Flor do Nascimento. Barcelona: Gedisa, 1990, pp. 155-161. Dimensões/ Helena Amaral da Fontoura (org.). Rio de Janeiro: ANPEd Nacional, 2011b.

KOHAN, W. O. "O que pode um professor?". Deleuze pensa a educação, Ed. Segmento, p. 48-57, 2007.

MOEHLECKE, V. Oficinar. In: FONSECA, T. M. G.; NASCIMENTO, M. L.; MARASCHIN, C. Pesquisar na diferença. Sulina. Porto Alegre, 2015.

MUNDI, A. Storyboard perfeito: o primeiro passo para uma animação perfeita. 2013. Disponível em: <http://www.animamundi.com.br/pt/blog/storyboard- perfeito-oprimeiro-passo-para-uma-animacao-perfeita/>. Acesso em: 25 out. 2018.

PASSOS, E.; BARROS, R. B. de. Por uma Política da Narratividade. In: PASSOS, E.; KASTRUP, V.; ESCOSSIA, L da (orgs.). Pistas do Método da Cartografia: Pesquisaintervenção e produção de subjetividade. Porto Alegre, Sulina, 2009.

QUADROS, R. Educação de surdos: efeitos de modalidade e práticas pedagógicas. In: MENDES, E. G.; ALMEIDA, M. A.; WILLIAMS, L. C. de A. (org.). Temas em educação especial IV. São Carlos: EdUFSCar, p. 55-61. 2004. Disponível em: $<$ http://www.porsinal.pt/index.php?ps=artigos\&idt $=$ artc\&cat $=7 \&$ idart $=50>$. Acesso em: 26 set. 2017.

RAUGUST, M. B. As diferentes formas de constituição de subjetividades surdas: a arte e a experiência visual em questão. In: LEBEDEFF, T. B. (org.). Letramento Visual e Surdez. Rio de Janeiro. Wak Editora, 2017.

SKLIAR, C. Los sentidos implicados en el estar-juntos de la educación. Revista Educación y Pedagogía, v. 22, n. 56, jan./abr., 2010.

STROBEL, K. As imagens do Outro sobre a cultura surda. Florianópolis. Edu da UFSC, 2016. 
VEYNE, P. Foucault: seu pensamento, sua pessoa. Tradução de Marcelo Jacques de Morais. Rio de Janeiro: Civilização Brasileira, 2014.

\begin{abstract}
i Doutora em Educação e Professora Associada da Universidade do Estado do Rio de Janeiro e pesquisadora procientista da mesma instituição. Psicóloga formada pela Universidad Nacional de Córdoba/Argentina. Lotada no Departamento de Educação da Faculdade do Formação de Professores (UERJ/FFP/DEDU) participa de projetos de ensino, pesquisa e extensão na Licenciatura em Pedagogia e atua como professora efetiva na Linha Políticas, Direitos e Desigualdades do Programa de Pós-Graduação em Educação - Processos formativos e desigualdades sociais do qual foi coordenadora desde 2016 até 2020. Faz parte do Coletivo "Diferenças e Alteridade na Educação" e do Grupo de Pesquisa Vozes da Educação (CNPq) Se interessa pelas políticas, poéticas e práticas na/da diferença, alteridade e experiência na educação, e na produção de políticas narrativas outras para contar a prática e a pesquisa em educação. É membro da Red Interuniversitaria Lationoamericana y de Caribe sobre Discapacidad y Derechos Humanos e da Red de Científicxs Argentinxs en Brasil- Programa RAICES (Red de Argentinas/os Investigadoras/es y Científicas/os en el Exterior) dependente do Ministerio de Ciencia, tecnologia e innovación do Governo da República Argentina. Coordena dois convenios internacionais com a UNER e a UPC/Argentina.

ii Doutoranda em Educação pelo Programa de Pós-Graduação em Educação Processos formativos e Desigualdades Sociais da UERJ-FFP na Linha de Pesquisa Política, Direito e Desigualdades; Mestra em Educação pelo mesmo programa na UERJ-FFP. Pós-graduada (lato sensu) em Libras (Língua Brasileira de Sinais). Graduada em Pedagogia pela Universidade Federal Fluminense (2011). Bailarina da Cia Holos de Dança e Teatro Inclusivo. Integrante do Grupo de Pesquisa Coletivo, Diferenças e Alteridades na Educação (UERJ-FFP) e do NUEDIS-CNPq (Núcleo de Estudos em Diversidade e Inclusão de Surdos) na UFF. Professora de Educação Infantil na rede municipal de Niterói atuando na Sala de Recursos e professora de apoio especializado na Educação de Jovens e Adultos.
\end{abstract}

Como citar esse artigo:

RIBETTO, Anelice; MARTINS, Arina. A produção de oficinas de animação com estudantes surdos na escola pública. Revista Digital do LAV, Santa Maria: UFSM, v. 14, n. 2, p. 247262, mai./ago. 2021. 